\title{
Chinese Literati Painting
}

\author{
Wenxiu Li \\ School of Art and Design \\ Huanghe Science and Technology College \\ Zhengzhou, China \\ e-mail: lads156@126.com
}

\begin{abstract}
Chinese literati painting is not the same as traditional Chinese painting, it is just a part of the whole system of Chinese painting; Chinese painting is not equivalent to literati painting, it is the general name of the different painting categories which generated form Chinese traditional culture. As an art category, Chinese literati painting is amazing, but it is full of negative thoughts with a fragile nature. Chinese literati painting only has the history of more than one thousand years, but the history of Chinese painting should be ten thousand.
\end{abstract}

Keywords-Chinese painting; Literati painting; New literati painting

Learning and absorbing traditional Chinese painting is the outlet of developing contemporary Chinese painting .Over thousand years'development, Chinese literati painting has establised its mainstream status. We are inclined to call Chinese painting as literati painting, literati painting is also Chinese freehand brushwork painting. And we think the literati freehand brushwork painting is the traditional Chinese painting and all of Chinese painting, which is a one-sided understanding. In Chinese painting there are not only literati painting but also folk and religious paintings, etc. These paintings provide rich referencial resources for contemporary Chinese painting. The tradition of taking literati painting as Chinese painting will affect the development of contemporary Chinese painting, thus it is important to demonstrate their relationship and nature.

\section{THE RELATION BETWEEN LITERATI PAINTING, CHINESE PAINTING AND PAINTING FEATURING CHINESE CHARACTERISTICS}

Talking of Chinese painting, it is natural to connect with writing brushes, ink sticks, paper and inkstones, poets, books and etc, which is a very interesting issue because ordinary people and painters are easily guided to misunderstand. We are more likely to associate with a picture with old men being busy doing with palettes, wearing Tang suit, tasting strong tea when talking of traditional Chinese painters; We naturally think of Zhu Ta, Shi Tao, and Qi Baishi, those outstanding painters when talking of the history of Chinese traditional painting. All these are misunderstandings because Literati painting does not equal to Chinese painting, Chinese painting does not equal to Literati paintings, either.

Chinese painting refers to those paintings that posses typical characteristics influenced by Chinese unique culture and history no matter from which perspectives, literally or culturally, which are distinguished with those paintings that are influenced by cultures and history like Egypt, Greece, Babylon. According to the understanding of the authors, the definition of Chinese painting is: those paintings which are rooted in the long history of Chinese civilization, boost typical Chinese culture and visual attributes and are influenced by past statesmen, thinkers, intellectuals and various literary genres(especially poets) with decorations and indoctrinations embodied in its content as well as styles. The paintings include: Paintings of architectures and utensils decorations (such as the early paintings and architectures); Religious paintings(such as Dunhuang grotto murals and Yongle temple paintings); Paintings by professional painter(such as Court paintings during Qin and Han Dynasties and Qin Dynasty with landscape, figures and flowers and birds, but different from Literati paintings); Literati painting(mainly refers to paintings which started from Northern Song Dynasty, prevailed in Yuan, Ming and Qing Dynasties)and folk paintings. While Literati painting mainly formulated in the end of the Five Dynasties, the early Song dynasty, based on tools like writing brushes, ink sticks, paper and inkstones, advocated by Sushi, Mifei etc.

From the above, Literati painting is just a part in the long history of Chinese painting and brilliant painting system. Literati painting does not equal to Chinese painting. While Literati painting, the signal of Chinese painting, obviously mislead a lot of people, which means Chinese painting does not equal to Literati painting as well as writing brushes, ink sticks, paper and inkstones, either. Thus, Chinese painting is the kind of paintings which influenced by Chinese traditional culture whereas Chinese painting does not equal to paintings featuring Chinese characteristics. Chinese painting relates to cultural concept whereas paintings featuring Chinese characteristics relate to geographical concepts.

\section{THE NATURE AND SIGNIFICANCE OF LITERATI PAINTING}

It is a common sense that literati painting was produced in Song dynasty, but for the reason why it was produced in Song dynasty, different people have different opinions.

As we all know, the official history of Chinese painting originated from the very beginning of the cross period Han and Jin Dynasties. At that time, Wu Daozi and Gu kaizhi were regarded as the representative figures of Chinese painting, and since then the Chinese painting entered into a new system, and 
emerged a large number of theorists and writings. Gradually there appeared some new characters, such as landscape, flowers and birds which derived from former painting pictures. But why the literati painting appeared in the five hundred years later? Everything has its own development regularity which behind the occurrence, the decisive role who played behind the art is the culture and the political environment at that time. As we know, a glass of wine relieved Zhao Kuangyin's threat and sent the literati to local region to do management, the safe time of Northern Song Dynasty is short, it had strong enemies form different aspects. Literatus are powerless, in a sense it caused the emergence and development of $\mathrm{Ci}$ and literati painting. In Song dynasty, the cultural atmosphere was relatively free and emphasizing on personal experience.[1] This is also a more important factor for the literati painters to express their opinions directly. Of course, many literatus were not satisfied in political affairs, which forced them to focus on pens and ink, So, the nature of literati painting is a self expression which can help to eliminate their unhappiness about their failure on official careers.

Compared with academic painters and their emphasis on rigorous technicals and modeled after their teachers [picture1], literati painters who did not stick to rules but just for inner pleasure, they were not just chasing for the gorgeous creations. This style gave a dynamic blood to the culture indeed at that time. The literati painters were mostly not professional painters, so that also made the literati painting was initially emphasized a more free natural and unrestrained feeling[picture2]. Literati painters were not professional painters, but they were relatively good at calligraphy pen and ink techniques on art, which made the literati painting was born with an abstract quality. That was undoubtedly a positive development of the arts.

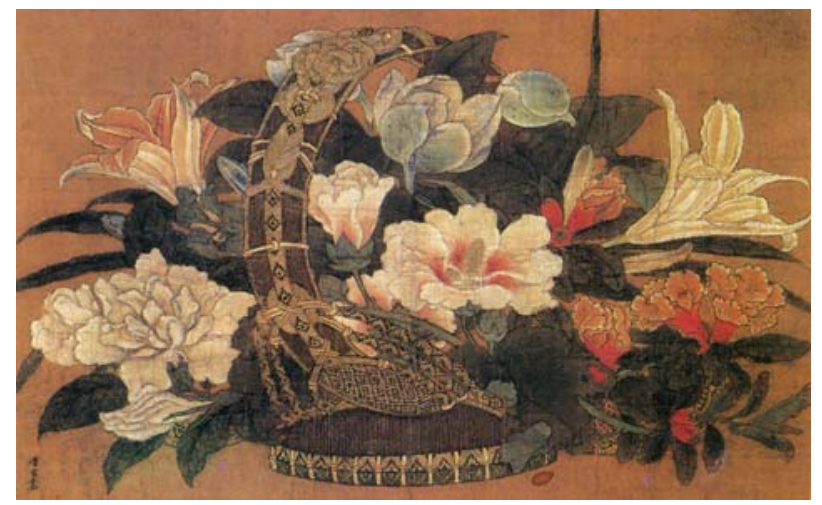

Picture.1. “Flower Basket” lisong (Song dynasty)

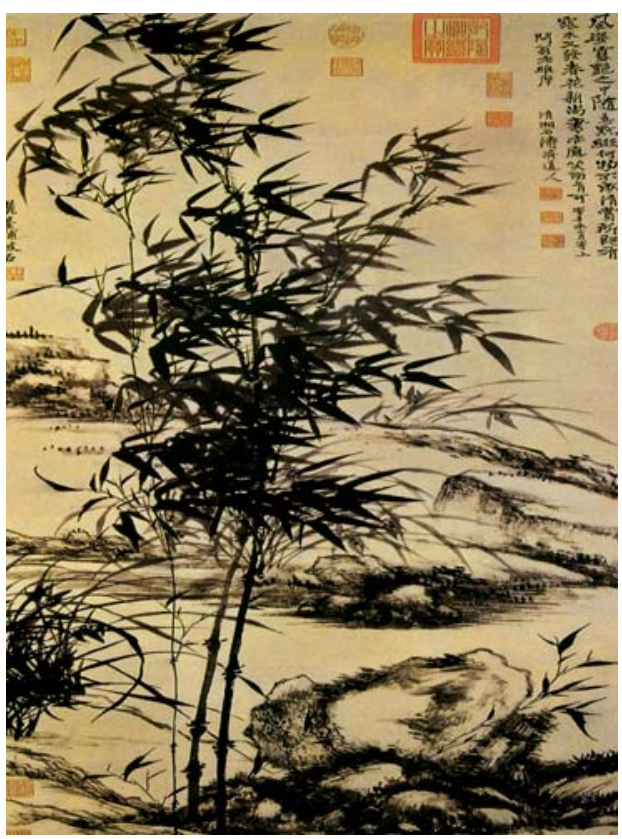

Picture.2. “Orchid and Bamboo” Shitao(Qing dynasty)

Literati painting is not the representative of Chinese culture, it is essentially fragile and full of negative thoughts. It is difficult for literati painting to carry the burden of culture, just like the French do not think Boucher and Rococo art is representative of the French spirit. As an art, literati painting is terrific, but as a part of culture, it is undoubtedly a pale skin cowardly scholar!

In addition, there are too many misunderstandings in the "literati" painting and "literati painting", literati painting was not an independent painting species when it was born, some of the basic conditions of literati painting that we have already mentioned above, so at first, literati painting emphasized on its literati, rather than painting itself. However, after the Yuan and Ming Dynasties, literati painting had undergone great changes, the term "literati painting" were more likely to be used to emphasize painting itself. At that time, the painters were still literati, but the painting had been their main career, Therefore, the development of literati painting gradually undergone a qualitative change, especially after the formation of a variety of painting later, the original meaning of literati painting had been completely digested. So the "literati" painting turned into "literati painting".

There appeared a cultural phenomenon in the late 1980s and early 1990s. Bian Pingshan, a painter from Beijing often chat with Wang Heping(a Fuzhou painter ) and Bei Yu(a Hebei painter) in his "Ping Shan Bookstore", because they shared the same idea and had many other things in common, they decided to sponsor a Chinese painting exhibition. And then with the agreement of Wang Mengji and Fang Jun[picture3], they decided to appoint the Tianjin painter Huo Chunyang as the organizer to arrange the exhibition at the Tianjin Academy of Fine Arts. This was the beginning of the new "literati painting". 


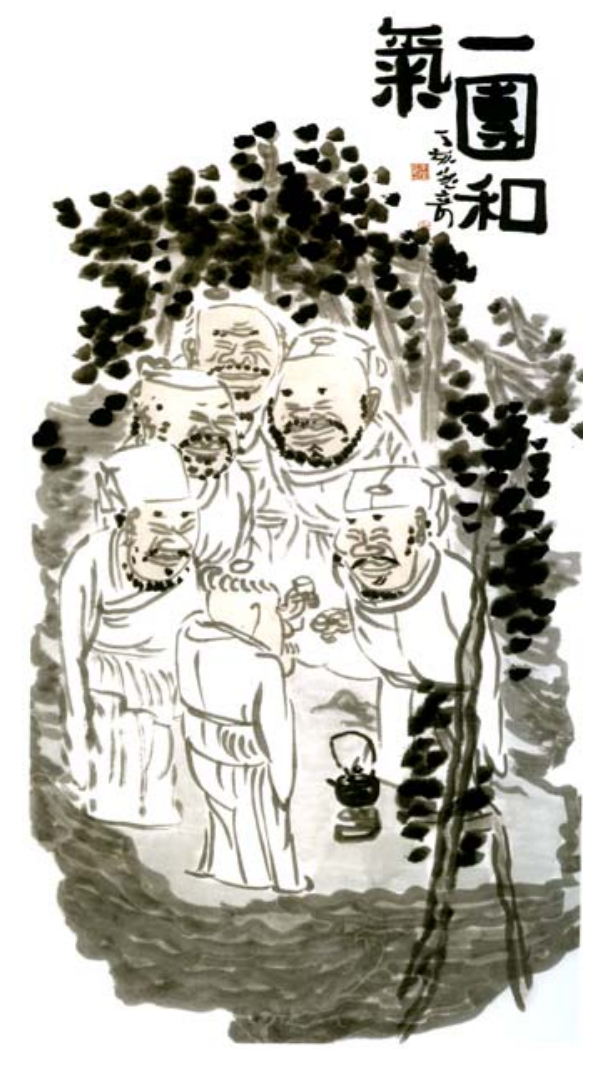

Picture.3. “Keeping on Good Terms” Wang mengqi (Modern Times)

What does new literati painting represent? It is generally felt claustrophobic, and not clearly to defined the characteristics of "new literati painting". Is it a new "literati painting" or a new "literati's painting”? Liu Xiaochun believed that the emergence of new literati painting is a backwash against the realistic approach. it also differs from the pure abstract ink painting, it is primarily a reevaluation of traditional culture. It emphasizes the modern realism and served as a complementary. Second, the "new literati painting" is an advanced version of public ink painting[2]. The "new literati painting", of course, is the result from the contradiction between intellectuals and the reality. Lang Shaojun believed that "new literati painting" showed a tendency of returning to tradition, and it was an innovation for contemporary art.

\section{THE DEVELOPMENT WAY OF CHINESE PAINTING}

Reform and opening up policy has brought the unprecedented impact on the Chinese traditional thought, culture, public life and art. Wu guanzhong, Li Xiaoshan announced the death and digestion of traditional art from various angles. Of course here the digestion or death is only the conclusion under globalization context after we opening up to the outside world and being influenced by the huge impact of the western culture. So the conclusion has a lot of radical and western ideological trend under the influence of blank and impatience. It is impossible to avoid the effect of the time, moreover, from the level of cognition, all thoughts and opinions are uncertain, incomplete, especially in the 80s. So, What is the fundamental problem of traditional Chinese painting? The predicament of Chinese painting actually is the embarrassment of Chinese culture. This problem has existed from the very beginning of the collision between the modern western civilization and the Chinese ancient traditional culture. The thought such as "western learning introduced into China" didn't solve the cultural conflict. On the contrary, it made the conflict between the two different culture systems becomes more acute. "May 4th" made an unprecedented innovation, but it is still based on a self-pity identity go up in the face of western advanced culture, and the major problems it faces is not cultural difference, cultural difference is a kind of equal dialogue. The fundamental problem of the May 4th movement is a cultural innovation caused by the inequality between east and west cultures, its purpose is to hope that China can be powerful slowly to get rid of humiliation. After Marx's thoughts being introduced into China for the purpose of saving the nation, it is also too busy to consider the culture. Western culture has only a partial impact on China at that time, the influence of Chinese traditional culture and its position is still strong, so in the first 50 years of 20th century, Chinese painting still had a strong impact.

The cultural revolution is a political movement, the cultural conflicts under the mask of politics are not obvious, although for many traditional Chinese painters, the cultural revolution is a nightmare, which is not ask a person disoriented and made no choice. After the reform and opening to the outside world, culture nightmare is the panic under the digestion of standards. Then the whole western culture system are poured into this piece of the continent like a typhoon, without warning.

In the face of Andy warhol, lausanne, and powys, where pens and inks can head for? In the face of existentialism and postmodernism, how the "nature and humanity" can continue their glorious? At the same time, when the square table changed into a glass tea table, when the teapot changed into coffee pot, a hanging traditional Chinese painting also seemed to let a person feel uncomfortable. In the face of consumer culture becomes the mainstream culture of China and the world today, Chinese painting can only be embarrassing, because it came from a different culture. The "artistic conception" in the Chinese painting were incompatible with contemporary culture, So when a culture is no longer existing in the original environment, when it cannot be understanding by contemporary people, this cultural regeneration, either or destroyed! However, it was hard to destroy, it's harder to regeneration. The culture is impossible to stay unchanged in a new environment, it will feel confused about what to do, and it is painful.

Zhuang zi's philosophy and Chinese poetry has created today's feature of Chinese paintings (literati painting), but can the philosophy of zhuangzi represent all of the Chinese culture? Can the Chinese painting which absorbed zhuangzi's philosophy represent all of the zhuang zi's philosophy? Is far from enough. "Nature and humanity" is certainly not endless, 
god have changed, if people are still the same, how can they combined in one ? Each era has its own culture, there is an old saying --"Nature does not change, neither does the Way. Nature changed; However, can the way still be same?

Let's look back and talk about traditional culture, zhuangzi and the old style poems were impossible to represent the Chinese culture, what's more, how could a word of "nature and humanity" explain all of Chinese culture? Zhuangzi's philosophy is a complex system, the traditional Chinese culture is a much larger system. Hundred Schools of Thought in Pre-Qin Period cannot represent the Chinese culture, how could Taoism do that. Needless to say the artists who have little knowledge about Taoism.

Today, I want to read some books about western modern literature and art, that shouldn't be tampering.We should give up the narrow understanding of Taoism and look deep at the real Chinese traditional culture, that is the right way to follow. Of course, some further development in mountains, waters and some subjects outside of grapes, eagles, four gentlemen could get more benefits. They should also change their ideas, the beautiful patterns on the architectures and pre-qin outstanding works of art should also considered as Chinese paintings.

Chinese Southern School painting only has the history of more than one thousand years, but the the history of real Chinese painting should be ten thousand. The real Chinese painting not only possess the passed ten thousand years, but also possess the ten thousand years in the future after we really understand the essence of Chinese culture.

\section{REFERENCES}

[1] Hong Zaixin.The Chinese art history [M]. Hongzhou: China academy of fine arts press, 2000: 193-194.

[2] Liu xiaoqun. Two Main Systems of Chinese Traditional Painting . selected from Argument on Chinese Traditional Painting. - Collection of Papers of International Symposium on contemporary Chinese painting[M]. Hong Kong: The Art Department of University of Hong Kong, The Art Department of Chinese University Hong Kong, 2002: 189. 